\title{
Spatial Frank vectorcardiogram in left posterior fascicular block Criteria and correlation with clinical and electrocardiographic data ${ }^{1}$
}

\author{
CHRISTIAN R. BROHET,2 AND PIERRE ARNAUD
}

From the 'Research Group on the electrical activity of the heart', Institut National de la Santé et de la Recherche Médicale, U.121, Hôpital Cardio-vasculaire, Lyons, France

Computer processing of spatial QRS parameters (Frank vectorcardiogram) was used to study left posterior fascicular block. The best set of vectorcardiographic criteria was sought in order to characterise the classic pattern of left posterior fascicular block.

Using these criteria, 18 cases were selected from a group of 4600 patients and 340 healthy subjects; isolated left posterior fascicular block was seen in 10 cases, and was associated with right bundle-branch block in 8 cases.

It is shown that some external factors can influence the aspect of the spatial QRS loop in left posterior fascicular block: cardiomegaly tends to produce a superior displacement of the main QRS forces: right bundle-branch block enhances the superior displacement of the initial forces and shifts the main QRS forces more anteriorly and to the right. The 'masquerading effect' of the left posterior fascicular block on a concomitant inferior myocardial infarct was also shown.

The most important diagnostic feature was the opposite direction of the initial forces (left anterosuperior) and the maximal vector (right postero-inferior): the angle between these two vectors averaged $152^{\circ}$. Other criteria, such as the direction of rotation or the axis of the frontal loop, the vertical direction of the spatial loop, the presence of a $Q$ wave in leads II, III, and aVF of the electrocardiogram, are not mandatory for the diagnosis of left posterior fascicular block.

After the preliminary report of Pryor and Blount (1966), the concept of left fascicular block was introduced by Rosenbaum et al. (1968). Many papers have been published on left anterior fascicular block but left posterior fascicular block has been less extensively studied. The latter is much rarer and the sensitivity and specificity of the electrocardiographic criteria of left posterior fascicular block are still uncertain. For instance, rightward deviation of the mean QRS axis, generally considered as a major criterion, is present in other conditions such as right ventricular overload or with a distinctly vertical position of the heart; also, criteria based on the configuration of the

Received for publication 10 June 1976

'Part of this study has been presented at the 7th European Congress of Cardiology (Amsterdam, June 1976).

'Current address: Cardio-Pulmonary Laboratory, Cliniques Universitaires St. Pierre, Brusselsestraat, 69, B 3000 Leuven, Belgium. initial segment of the QRS lose their validity in the presence of myocardial infarction as this also affects the early part of the QRS complex.

Consequently, there is no consensus about the electrocardiographic criteria of left posterior fascicular block: rightward shift of the mean QRS axis beyond $+90^{\circ}$ is not required by some authors (Medrano et al., 1972), and leftward orientation of the initial part of the QRS is not mandatory according to others (Fernandez et al., 1972). Indeed, the actual presence of left posterior fascicular block in some reported cases can be questioned.

In this study, a specific methodology has been used in order to avoid the problems resulting from non-validated electrocardiographic criteria for the diagnosis of left posterior fascicular block. The cases of left posterior fascicular block were selected according to several vectorcardiographic criteria 
and a quantitative analysis of the spatial QRS loop was performed; the results of the analysis have been compared with published data.

\section{Subjects and methods}

\section{RECORDING TECHNIQUE}

In addition to the conventional 12 lead electrocardiogram the vectorcardiograms were recorded using the corrected orthogonal lead system of Frank. The patients were lying in a semirecumbent position, with the thorax at $45^{\circ}$ from the horizontal level; the 4th intercostal space was used. The three planar vectorcardiographic loops were directly inscribed on paper by means of a digital system, with a sampling rate of 500 per second (Arnaud et al., 1968). Each patient had a second recording which provided the onset of the QRS with an increased magnification and a sampling rate of 1000 per second. The scalar components $\mathrm{X}, \mathrm{Y}$, and $\mathrm{Z}$ were simultaneously recorded on an ElemaSchonander electrocardiograph, at a speed of $100 \mathrm{~mm} / \mathrm{s}$.

\section{COMPUTER PROCESSING}

For each recording, a QRS-T complex was processed by a PDP/8 computer. ${ }^{1}$

The programme 'EXPV', developed in this laboratory, computes 180 vectorcardiographic measurements (Rubel et al., 1975). The spatial QRS loop is characterised in reference to the 8 octants of the tridimensional space, and for each octant the following parameters are computed: the area developed by this segment of curve (absolute area and relative area, that is its percentage of the total QRS area); the duration in this octant (absolute and relative duration); and the maximal octantal vector: in terms of its magnitude (absolute and relative value), its orientation, and its time of occurrence from the onset of QRS. Among the other measurements, the more important are: the maximal spatial and the half-area spatial QRS vectors, their magnitude, orientation, and time of occurrence; the QRS duration and the half-time QRS vector; and the direction of rotation of the planar QRS loops. Thereafter, three different curves are derived as a function of time (sampling at 500 per second): the curve of the amplitude of the spatial instantaneous vectors, the curve of the linear velocity of the spatial QRS loop, and the curve of the elementary areas.

The reference frame for angular values is as follows: the azimuth angle, that is the angle

\footnotetext{
${ }^{2}$ Digital Equipment Corporation.
}

between the projection of a vector on the horizontal plane and the transverse $\mathrm{X}$ axis is measured from 0 to $360^{\circ}$ in a clockwise direction starting from the left extremity of the $\mathrm{X}$ lead. The elevation angle, that is the angle drawn by the spatial vector with the horizontal plane-is measured from 0 to $+90^{\circ}$ below the horizontal plane and from $0^{\circ}$ to $-90^{\circ}$ above this plane (negative value $=$ superior direction). The 'initial QRS segment' is defined as the vector located at the point having the maximal superior altitude, that is at the highest value of the vertical $\mathrm{Y}$ component in its initial deflection.

\section{POPULATIONS STUDIED}

(1) A series of 4600 consecutive patients with various heart diseases drawn from the wards of the Cardiovascular Hospital of Lyons.

(2) A group of 340 healthy active subjects.

We excluded from this study cases presenting: (1) right ventricular hypertrophy or overload, suggested by clinical and/or haemodynamic data; (2) chronic obstructive pulmonary disease; (3) a vertical heart on chest $x$-ray examination.

Furthermore, we excluded all the cases where the diagnosis of left posterior fascicular block could not be found for one of the following reasons: (1) QRS duration less than $90 \mathrm{~ms}$; (2) absence of accurate diagnostic information; (3) presence of complete or incomplete left bundle-branch block; (4) presence of a pre-excitation syndrome; (5) anterior, anteroseptal, or anterolateral wall myocardial infarction (which could cause loss of initial anterior forces), or true posterior wall myocardial infarction (because of its peculiar effect on the horizontal QRS loop). Cases of inferior wall myocardial infarction were retained.

\section{PRELIMINARY SELECTION OF} VECTORCARDIOGRAMS

A preliminary selection was made on the basis of the following provisional vectorcardiographic criteria, derived from the accepted definition of left posterior fascicular block (Castellanos and Lemberg, 1971; Polu et al., 1972; Pryor, 1972; Varriale and Kennedy, 1972; Chou et al., 1974; Nicolai et al., 1974): (a) initial QRS segment oriented to the left, anteriorly (left anterior quadrant of horizontal plane), and superiorly (left superior quadrant of frontal plane), or sometimes horizontally and to the left in the frontal plane, and (b) maximal QRS vector oriented to the right, or QRS area greater in the right than in the left half of the electrical field, or mean QRS axis of the electrocardiogram equal to or superior to $+90^{\circ}$. 
DEFINITION OF NEW SERIES OF

VECTORCARDIOGRAPHIC CRITERIA OF LEFT

POSTERIOR FASCICULAR BLOCK

A detailed computer analysis of the various vectorcardiographic measurements was then performed in the cases selected on the basis of these provisional criteria. The results of this analysis combined with additional information collected from electrocardiographic, clinical, and radiological data allowed us to define the following criteria for the electrocardiographic-vectorcardiographic diagnosis of left posterior fascicular block.

\section{Criterion $A$}

The initial deflection of the QRS loop on the vectorcardiogram must be oriented anteriorly, superiorly, and to the left. In the frontal plane, a straight horizontal direction of the early vectors (null value of the elevation angle of the "first segment vector') is acceptable, provided that both the maximal and the half-area $Q R S$ vectors are located in the right half of the electrical field.

\section{Criterion $B$}

Both the maximal and the half area $Q R S$ vectors must be oriented to the right, that is located in the right half of the horizontal and frontal planes. The half area vector could be differently oriented, provided that the mean QRS axis of the electrocardiogram was equal to or superior to $+90^{\circ}$.

CRITERIA OF AN ASSOCIATED COMPLETE

RIGHT BUNDLE-BRANCH BLOCK

For the diagnosis of a complete right bundlebranch block, all the following criteria must be satisfied: (1) QRS duration $\geqslant 115 \mathrm{~ms}$ in the adult (94 $\mathrm{ms}$ in a 7-year-old child-case 12, see below), (2) delay of the inscription of the late $Q R S$ vectors, visualised in all three planes, and (3) presence of a plateau, with or without oscillations, on the late part (beyond $85 \mathrm{~ms}$ ) of the linear velocity curve of the spatial QRS loop.

\section{DESCRIPTION OF CASES SELECTED}

From the hospital population of 4600 patients, 18 cases with evidence of left posterior fascicular block $(0.39 \%)$ were selected on the basis of these criteria. No cases were found in the group of 340 normal subjects. The 18 records were further divided into 2 groups: group A (10 cases) with isolated left posterior fascicular block (cases 1 to 10); group B (8 cases) with left posterior fascicular block + complete right bundle-branch block (cases 11 to 18).

${ }^{1}$ In normal individuals, the terminal part of this curve is less delayed and always decreases steeply.
There were 15 male and 3 female patients whose ages varied from 7 to 91 years. As seen in the study of Lopes et al. (1974), the mean age was lower in group A (41.8) than in group B (52.9). The clinical and pathological findings, and the electrocardiographic diagnoses are listed in Tables 1 and 2. Fig. 1A and B present the vectorcardiographic and electrocardiographic features of a 35-year-old patient (case 6) and show the typical orientation of the initial segment vector and the distinct right displacement of the main QRS forces.

\section{Results}

The results of the vectorcardiographic and electrocardiographic analyses are presented in Table 3 (group A, isolated left posterior fascicular block; and group B, left posterior fascicular block + complete right bundle-branch block).

The initial segment vector of the spatial $Q R S$ loop had an azimuth angle (AZ) varying from 0 to $90^{\circ}$. The mean value was higher in group $A$ than in group B: $57 \cdot 1^{\circ}$, as opposed to $38.9^{\circ}$.

The elevation angle varied from $0^{\circ}$ (straight horizontal orientation in the frontal plane) to $-77^{\circ}$ (superior orientation). The mean value was lower in group $A\left(-17 \cdot 1^{\circ}\right)$ than in group $B\left(-33 \cdot 5^{\circ}\right)$.

The angle between the initial segment vector and the maximal $Q R S$ vector varied from $75^{\circ}$ to $176^{\circ}$ (mean $=152.9^{\circ}$ in group $A$ and $151.9^{\circ}$ in group B).

The maximal vector located in the left anterosuperior octant, in the early part of the spatial QRS loop, had a relative magnitude (RM) varying from 6 to 70 per cent of the maximal spatial QRS magnitude. The mean value was 24.3 per cent in group $\mathrm{A}$ and 29.5 per cent in group $\mathrm{B}$.

The relative area $(R A)$, that is the area drawn by the initial segment of the spatial QRS loop in the left anterosuperior octant as compared with the total QRS loop area, averaged 3.8 per cent in group $\mathrm{A}$ and 3.5 per cent in group $\mathrm{B}$. The value was less than 1 per cent in 4 cases.

The QRS loop remained in this left anterosuperior octant during a period (absolute duration) varying from 10 to $52 \mathrm{~ms}$ (mean $20.6 \mathrm{~ms}$ in group $\mathrm{A}$ and $23.4 \mathrm{~ms}$ in group B). This represented 6 to 47 per cent of the total QRS loop duration (relative duration; mean $=20.8 \%$ in group $A$ and $16.6 \%$ in group B).

The orientation of the maximal $Q R S$ vector was mainly toward the right posteroinferior octant of the space. Its azimuth angle was between $146^{\circ}$ and $260^{\circ}$ (mean in group A $243.7^{\circ}$ and in group B $197 \cdot 6^{\circ}$ ). Its elevation angle varied from $68^{\circ}$ (below the horizontal plane) to $-6^{\circ}$ (above the horizontal 
Table 1 Clinical and pathological findings, electrocardiographic diagnosis of group $A$; isolated left posterior fascicular block

\begin{tabular}{|c|c|c|c|c|c|c|}
\hline $\begin{array}{l}\text { Case } \\
\text { No. }\end{array}$ & $\begin{array}{l}\text { Age } \\
(y)\end{array}$ & $\operatorname{Sex}$ & Clinical and pathological findings & $\begin{array}{l}\text { Electrocardiographic diagnosis } \\
\text { (apart from left posterior fascicular block) }\end{array}$ & $\begin{array}{l}P R \\
(m s)\end{array}$ & $\begin{array}{l}\text { Left ventricular } \\
\text { enlargement } \\
(x-\text { ray })\end{array}$ \\
\hline 1 & 18 & $M$ & Essential hypertension & Left ventricular hypertrophy & 110 & 一 \\
\hline 2 & 43 & $M$ & Hypertension, nephropathy & Left ventricular hypertrophy & 140 & + \\
\hline 3 & 13 & $\mathrm{M}$ & Supraventricular tachycardia-frequent bouts & $\begin{array}{l}\text { No WPW syndrome (His bundle recording) } \\
\text { transient tachycardia-dependent left } \\
\text { bundle-branch block }\end{array}$ & 140 & + \\
\hline 4 & 58 & $\mathbf{M}$ & $\begin{array}{l}\text { Severe calcific aortic stenosis: normal right- } \\
\text { sided pressures }\end{array}$ & Pronounced left ventricular hypertrophy & 180 & $++t$ \\
\hline 5 & 69 & $\mathbf{M}$ & $\begin{array}{l}\text { Coronary artery disease; old inferior wall } \\
\text { myocardial infarction-left ventricular } \\
\text { failure }\end{array}$ & Incomplete left bundle-branch block & 180 & - \\
\hline 6 & 35 & $M$ & $\begin{array}{l}\text { Severe calcific aortic stenosis; left ventricular } \\
\text { hypertrophy, aortic valve replacement- } \\
\text { post-surgical syncope }\end{array}$ & $\begin{array}{l}\text { Left ventricular hypertrophy; after surgery } \\
\text { right bundle-branch block and shift of } \\
\text { QRS axis }+20^{\circ} \text { to }+100^{\circ}\end{array}$ & 110 & - \\
\hline 7 & 41 & $\mathbf{F}$ & $\begin{array}{l}\text { Catheterisation and pulmonary angiography: } \\
\text { negative-during catheterisation junctional } \\
\text { (nodal superior) paroxysmal tachycardia }\end{array}$ & $\begin{array}{l}\text { Transient complete right bundle-branch } \\
\text { block (with QRS axis }+150^{\circ} \text { ) during } \\
\text { paroxysmal tachycardia; otherwise isolated } \\
\text { left posterior fascicular block }\end{array}$ & 140 & 一 \\
\hline 8 & 18 & $\mathbf{M}$ & $\begin{array}{l}\text { Primitive cardiomyopathy; left ventricular } \\
\text { failure; normal right-sided pressures }\end{array}$ & Left ventricular hypertrophy & 190 & $+t+$ \\
\hline 9 & 62 & $\mathbf{M}$ & $\begin{array}{l}\text { Coronary artery disease; several coronary } \\
\text { thromboses; left ventricular failure }\end{array}$ & $\begin{array}{l}\text { Incomplete right bundle-branch block with } \\
\text { left anterior fascicular block at first; } \\
\text { thereafter complete right bundle-branch } \\
\text { block with left anterior fascicular block; } \\
\text { finally intermittent right bundle-branch } \\
\text { block and permanent isolated left posterior } \\
\text { fascicular block }\end{array}$ & 230 & $+t+$ \\
\hline 10 & 61 & $\mathbf{M}$ & $\begin{array}{l}\text { Hypertension; severe coronary artery disease } \\
\text { (necropsy), old inferior wall myocardial } \\
\text { infarction, recent septal necrosis; left } \\
\text { ventricular hypertrophy }\end{array}$ & Inferior wall myocardial infarction & 140 & $+t+t$ \\
\hline
\end{tabular}

^For key, see Table 2.

plane) averaging $18.2^{\circ}$ in group $A$ and $30.2^{\circ}$ in group B.

The orientation of the half-area $Q R S$ vector was close to that of the maximal vector: the azimuth angle was in the range of $150^{\circ}$ to $324^{\circ}$ (mean $=250^{\circ}$ in group $A$ and $213.9^{\circ}$ in group B); the elevation angle varied from $81^{\circ}$ to $-15^{\circ}$ averaging $20.5^{\circ}$ in group $A$ and $43.9^{\circ}$ in group $B$.

As with the maximal and the half-area QRS vectors, the half-time $Q R S$ vectors were most often directed to the right posteroinferior octant (14 cases).

The mean $Q R S$ axis in the electrocardiogram varied from $+90^{\circ}$ to $180^{\circ}$ in 15 cases. In the remaining 3 cases it was, respectively, $+60^{\circ}$, $+80^{\circ}$, and $-140^{\circ}$. Its mean value was $+112^{\circ}$ in group $A$ and $+127.5^{\circ}$ in group B.

In adults, the relative area of the spatial $Q R S$ loop developing in the left half of the electrical field is normally greater than 75 per cent of the total QRS area. In these patients, lower values were observed (from $4 \%$ to $53 \%$; mean: $35.8 \%$ in group A and $24.6 \%$ in group B), again demonstrating the rightward deviation of the main QRS forces.

The rotation of the $Q R S$ loop in the frontal plane was clockwise in 15 cases, counterclockwise in 1 case, and figure-of- 8 in 2 cases. In the horizontal plane, the rotation was counterclockwise in 11 cases and figure-of- 8 in the remaining 7 cases.

The QRS duration was $90 \mathrm{~ms}$ in 3 cases: we believe that this value is compatible with the diagnosis of left posterior fascicular block. The mean value of the QRS duration was $97.1 \mathrm{~ms}$ in group $A$ and 146.5 in group B where a right bundle-branch block was associated with the left posterior fascicular block.

The time of occurrence of the maximal vector, from the onset of the QRS loop, varied from 44 to $105 \mathrm{~ms}$ (mean $53 \mathrm{~ms}$ in group $\mathrm{A}$, and $72 \mathrm{~ms}$ in group $\mathrm{B}$ ). It was greater than $50 \mathrm{~ms}$ in 12 cases (5 of the 10 cases of group A, and 7 of the 8 cases of group B), denoting a delay of the first part of the QRS loop preceding the maximal vector. This part was even longer than that following the maximal vector in 11 of the 18 cases.

The time of occurrence of the half-area vector was somewhat shorter: it varied from 32 to $92 \mathrm{~ms}$, averaging $49.5 \mathrm{~ms}$ in group $A$ and $64.9 \mathrm{~ms}$ in group B. The average time of occurrence of both the maximal and the half-area vectors was $17 \mathrm{~ms}$ greater in group B than in group A.

The magnitude of the maximal spatial $Q R S$ 
Table 2 Clinical and pathological findings, electrocardiographic diagnosis of group B : left posterior fascicular block + complete right bundle-branch block

\begin{tabular}{|c|c|c|c|c|c|c|}
\hline $\begin{array}{l}\text { Case } \\
\text { No. }\end{array}$ & $\begin{array}{l}\text { Age } \\
\text { (y) }\end{array}$ & $\operatorname{Sex}$ & Clinical and pathological findings & $\begin{array}{l}\text { Electrocardiographic diagnosis } \\
\text { (apart from left posterior fascicular block) }\end{array}$ & $\begin{array}{l}P R \\
(m s)\end{array}$ & $\begin{array}{l}\text { Left ventricular } \\
\text { enlargement } \\
(x-\text { ray })\end{array}$ \\
\hline 11 & 70 & $\mathbf{M}$ & Hypertension; Adams-Stokes syncope & $\begin{array}{l}\text { Isolated complete right bundle-branch block; } \\
\text { thereafter complete heart block followed } \\
\text { by } 4 / 1 \mathrm{AV} \text { block and complete right } \\
\text { bundle-branch block + left anterior } \\
\text { fascicular block; finally complete right } \\
\text { bundle-branch block + left posterior } \\
\text { fascicular block }\end{array}$ & 220 & 一 \\
\hline 12 & 7 & $\mathbf{M}$ & $\begin{array}{l}\text { Mitral regurgitation since birth; normal } \\
\text { right-sided pressures }\end{array}$ & $\begin{array}{l}\text { Unusual aspect: } Q R S \text { in } V 1 \text {, no } q \text { in } I, \text { aVL, } \\
\text { V5, V6 }\end{array}$ & 150 & + \\
\hline 13 & 54 & $\mathbf{M}$ & Adams-Stokes syncope & $\begin{array}{l}\text { Intermittent complete AV block; complete } \\
\text { right bundle-branch block; later on: } \\
\text { regression, only isolated left posterior } \\
\text { fascicular block }\end{array}$ & 170 & 一 \\
\hline 14 & 70 & $\mathbf{F}$ & $\begin{array}{l}\text { Aortic stenosis, hypertension, angina, left } \\
\text { ventricular failure }\end{array}$ & $\begin{array}{l}\text { Complete right bundle-branch block, axis } \\
\text { deviation undetermined }\left(-140^{\circ} \text { ?) }\right.\end{array}$ & 120 & + \\
\hline 15 & 41 & $\mathbf{M}$ & $\begin{array}{l}\text { Rheumatic mitral regurgitation, hypertension, } \\
\text { and glomerulonephritis }\end{array}$ & $\begin{array}{l}\text { Complete right bundle-branch block with } \\
\text { right axis deviation }\end{array}$ & 150 & + \\
\hline 16 & 36 & $\mathbf{M}$ & $\begin{array}{l}\text { No history of heart disease; Adams-Stokes } \\
\text { syncope }\end{array}$ & $\begin{array}{l}\text { Incomplete and intermittent AV block; } \\
\text { complete right bundle-branch block with } \\
\text { right axis deviation }\end{array}$ & 170 & 一 \\
\hline 17 & 91 & $\mathbf{F}$ & $\begin{array}{l}\text { Acute inferior wall myocardial infarction } \\
4 \text { days before vectorcardiogram }\end{array}$ & $\begin{array}{l}\text { Unstable AV block-permanent complete } \\
\text { right bundle-branch block; transitory left } \\
\text { anterior fascicular block, otherwise left } \\
\text { posterior fascicular block with shift of } \\
\text { QRS axis }-90^{\circ} \text { to }+120^{\circ}\end{array}$ & 170 & $++t$ \\
\hline 18 & 54 & $\mathbf{M}$ & $\begin{array}{l}\text { Hypertension, angina, left ventricular failure, } \\
\text { normal right-sided pressures }\end{array}$ & $\begin{array}{l}\text { First normal QRS axis and SIQIII pattern; } \\
\text { thereafter intermittent right bundle-branch } \\
\text { block and shift of QRS axis to }+140^{\circ} \text {. } \\
\text { Then complete right bundle-branch block } \\
\text { and QRS axis }+180^{\circ}\end{array}$ & 230 & +++ \\
\hline
\end{tabular}

Left ventricular enlargement: - nil; + moderate; +++ severe; ++++ very severe.

vector varied from 1.07 to $2 \cdot 80 \mathrm{mV}$, averaging 1.80 $\mathrm{mV}$.

As expected, the curve of the amplitude of the spatial instantaneous vectors was delayed in its terminal part in all cases with a right bundlebranch block. But the aspect of this curve was always normal, showing no irregularities, especially in its initial part.

The duration of the $P R$ interval was between 110 and $230 \mathrm{~ms}$ (mean value: $163 \mathrm{~ms}$ ). It was 180 or $190 \mathrm{~ms}$ in 3 cases, and 220 or $230 \mathrm{~ms}$ in 3 cases.

\section{Discussion}

This study confirms that left posterior fascicular block, as diagnosed from vectorcardiographic criteria, is rare whether isolated or associated with right bundle-branch block; it was observed in only 0.39 per cent of the patients in a specialised cardiac institute. Our criteria of selection, with exclusion of all cases with anterior wall myocardial infarction, could account in part for this. The real incidence of left posterior fascicular block in our centre probably approaches $0.45-0.50$ per cent, which agrees with the results of others using electrocardiographic criteria (Strickland et al., 1972; Rizzon et al., 1975). In contrast with the left anterosuperior fascicle, which is relatively vulnerable to anterior wall infarction (Rosenbaum et al., 1968; Bobba et al., 1972), we found that left posterior fascicular block was rare in inferior wall myocardial infarction (only 3 cases in our series).

The diagnosis of left posterior fascicular block is difficult, mainly because the commonly used electrocardiographic criteria lack specificity. In this study, we have attempted to define more valid criteria from the Frank vectorcardiogram rather than from the conventional 12 lead electrocardiogram and we have characterised the spatial QRS vector loop in left posterior fascicular block.

\section{CRITERION A: INITIAL PART OF QRS LOOP}

According to criterion $A$, the initial part of the QRS loop in left posterior fascicular block must be oriented anteriorly, superiorly, and to the left. This orientation results from the initial depolarisation depending only on the anterosuperior fascicle which activates the anterosuperior part of the left side of the septum and the adjacent anterior left ventricular wall (Scher, 1960; Rosenbaum 
et al., 1968; Lemberg et al., 1971; Medrano et al., 1971). Right bundle-branch block does not affect this sequence of septal activation (Rosenbaum et al., 1968; Cohen et al., 1968).

In this series, the initial segment of the spatial QRS loop and the maximal spatial $Q R S$ vector were oriented in opposite directions. In both groups, these two vectors formed an angle whose mean value was $152^{\circ}$, with a narrow range $\left(140^{\circ}\right.$ to $176^{\circ}$, after exclusion of two extreme cases). The presence of complete right bundle-branch block did not modify this particular relation between the initial and the maximal QRS vectors. In group B as compared with group A, the mean elevation angle showed an initial segment vector more superiorly oriented $\left(-33 \cdot 5^{\circ}\right.$ in group $B,-17 \cdot 1^{\circ}$ in group A) and a maximal $Q R S$ vector more in-
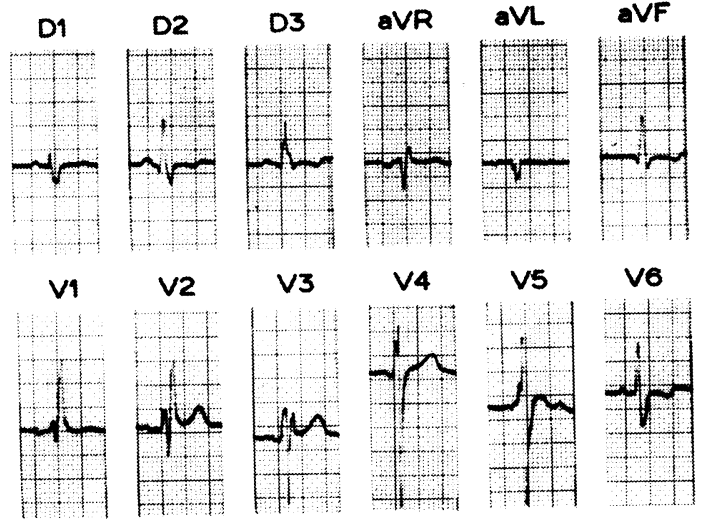

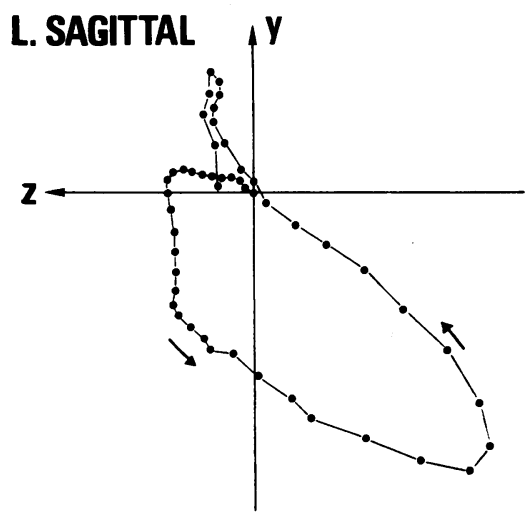

1B
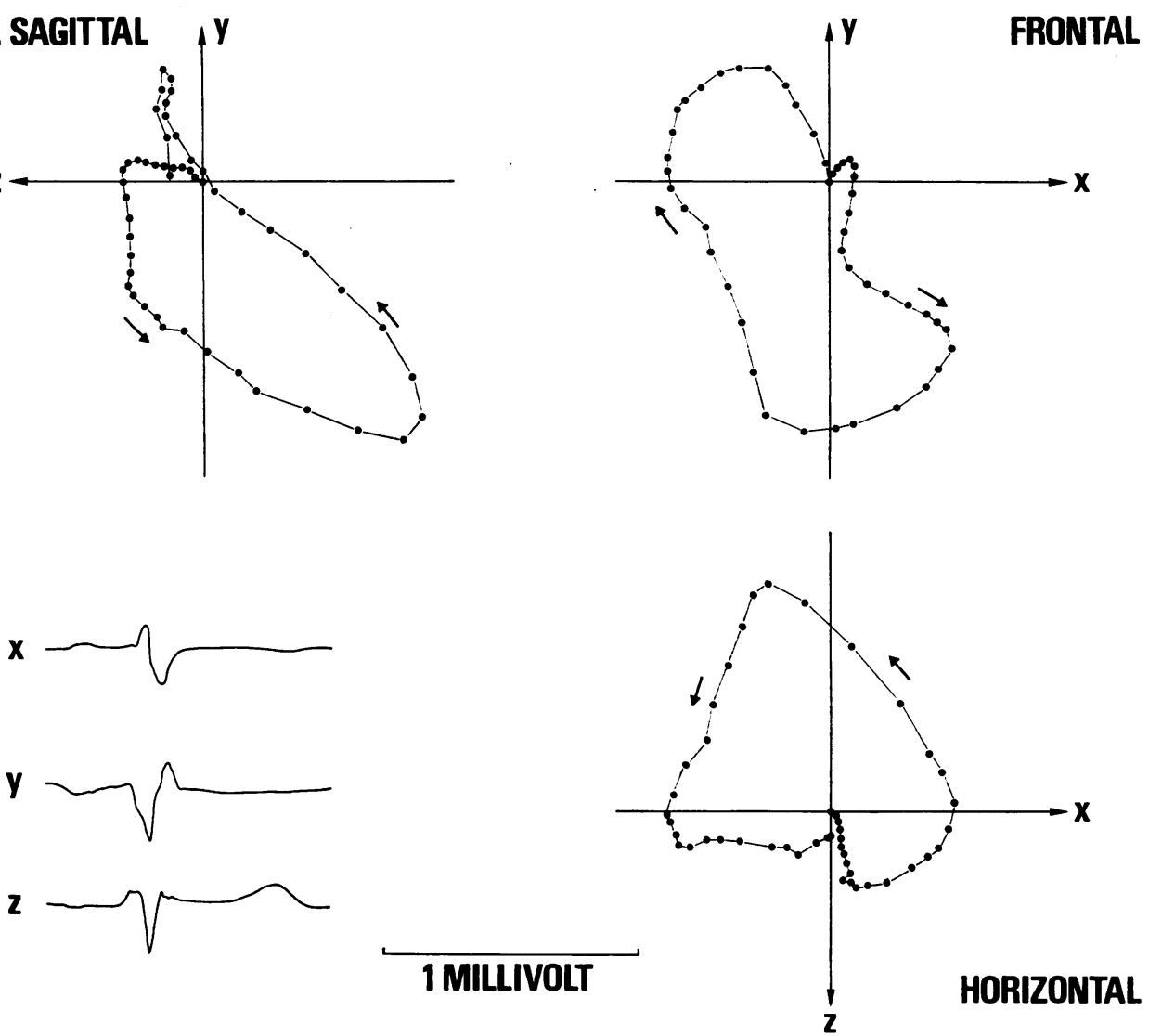

$1 \mathrm{~A}$

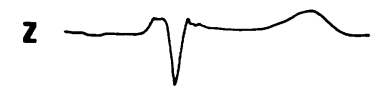

Fig. 1 (A) Frank QRS vectorcardiogram (Case 6). Plot time interval of 2 milliseconds. (B) Electrocardiogram, the same patient, who suffered from calcific aortic stenosis with a gradient of $170 \mathrm{mmHg}$, left ventricular hypertrophy, and poor contractility of both ventricles. After valve replacement (Björk prosthesis), he suffered from syncope, and a demand pacemaker was then inserted. The electrocardiogram before surgery showed left ventricular hypertrophy with a $Q R S$ axis of $+20^{\circ}$ and no ventricular conduction abnormalities. After surgery, right bundle-branch block occurred with a $Q R S$ duration of $0.12 \mathrm{~s}$, a shift of $Q R S$ axis to $+100^{\circ}$, and an SIQIII pattern. $(D 1,2,3=$ leads $I, I I, I I I$. 
Table 3

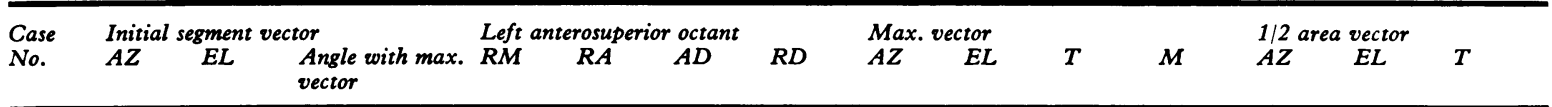

\begin{tabular}{|c|c|c|c|c|c|c|c|c|c|c|c|c|c|c|}
\hline \multicolumn{15}{|c|}{ Vectorcardiographic and electrocardiographic values of group $A$ (isolated left posterior fascicular block) } \\
\hline $\begin{array}{r}1 \\
2 \\
3 \\
4 \\
5 \\
6 \\
7 \\
8 \\
9 \\
10\end{array}$ & $\begin{array}{r}82 \\
72 \\
90 \\
39 \\
0 \\
80 \\
53 \\
67 \\
45 \\
43\end{array}$ & $\begin{array}{r}-40 \\
-16 \\
-33 \\
0 \\
-21 \\
-7 \\
-15 \\
-22 \\
0 \\
-17\end{array}$ & $\begin{array}{r}163 \\
168 \\
154 \\
161 \\
91 \\
142 \\
165 \\
173 \\
172 \\
140\end{array}$ & $\begin{array}{r}27 \\
28 \\
16 \\
18 \\
9 \\
21 \\
17 \\
17 \\
20 \\
70\end{array}$ & $\begin{array}{r}5 \\
1 \\
0 \\
1 \\
0 \\
1 \\
1 \\
1 \\
2 \\
26\end{array}$ & $\begin{array}{l}26 \\
20 \\
13 \\
12 \\
12 \\
18 \\
20 \\
13 \\
20 \\
52\end{array}$ & $\begin{array}{l}25 \\
22 \\
14 \\
13 \\
12 \\
17 \\
22 \\
14 \\
22 \\
47\end{array}$ & $\begin{array}{l}247 \\
256 \\
257 \\
253 \\
260 \\
253 \\
248 \\
241 \\
232 \\
190\end{array}$ & $\begin{array}{r}58 \\
4 \\
11 \\
4 \\
35 \\
44 \\
21 \\
15 \\
-4 \\
-6\end{array}$ & $\begin{array}{l}54 \\
50 \\
50 \\
63 \\
45 \\
56 \\
48 \\
45 \\
55 \\
64\end{array}$ & $\begin{array}{l}2 \cdot 80 \\
2 \cdot 11 \\
2 \cdot 32 \\
2 \cdot 63 \\
1 \cdot 82 \\
1 \cdot 37 \\
1 \cdot 51 \\
1 \cdot 42 \\
1 \cdot 07 \\
1 \cdot 10\end{array}$ & $\begin{array}{l}279 \\
270 \\
264 \\
261 \\
260 \\
253 \\
248 \\
242 \\
228 \\
195\end{array}$ & $\begin{array}{r}60 \\
13 \\
28 \\
4 \\
35 \\
44 \\
21 \\
7 \\
0 \\
-7\end{array}$ & $\begin{array}{l}48 \\
40 \\
40 \\
50 \\
45 \\
56 \\
48 \\
50 \\
50 \\
68\end{array}$ \\
\hline Mean & $57 \cdot 1$ & $-17 \cdot 1$ & 152.9 & $24 \cdot 3$ & 3.8 & 20.6 & 20.8 & $243 \cdot 7$ & $18 \cdot 2$ & 53 & 1.81 & 250 & 20.5 & 49.5 \\
\hline
\end{tabular}

\begin{tabular}{|c|c|c|c|c|c|c|c|c|c|c|c|c|c|c|}
\hline 11 & \multicolumn{3}{|c|}{ Vectorcardiographic and electrocardiographic values of group B (left posterior fascicular block + complete right bundle-branch block) } & 33 & 3 & 24 & 14 & 214 & 68 & 63 & 2.36 & & 81 & 49 \\
\hline 12 & 24 & -11 & 149 & 50 & 3 & 18 & 19 & 233 & 26 & 44 & $2 \cdot 13$ & 257 & 46 & 32 \\
\hline 13 & 64 & -42 & 168 & 43 & 13 & 43 & 34 & 226 & 46 & 75 & 2.01 & 225 & 50 & 70 \\
\hline 14 & 54 & -6 & 158 & 25 & 1 & 16 & 11 & 213 & 13 & 60 & 1.65 & 198 & 9 & 72 \\
\hline 15 & 68 & -37 & 75 & 59 & 7 & 35 & 23 & 146 & 0 & 105 & 1.07 & 191 & 68 & 68 \\
\hline 16 & 90 & -77 & 154 & 6 & 0 & 28 & 16 & 197 & 55 & 98 & $2 \cdot 70$ & 186 & 74 & 92 \\
\hline 17 & 0 & -30 & 176 & 8 & 0 & 13 & 10 & 185 & 34 & 53 & $2 \cdot 29$ & 180 & 38 & 48 \\
\hline 18 & 0 & 0 & 165 & 12 & 1 & 10 & 6 & 167 & 0 & 78 & 1.44 & 150 & -15 & 88 \\
\hline Mean & 38.9 & -33.5 & 151.9 & 29.5 & 3.5 & 23.4 & 16.6 & $197 \cdot 6$ & $30 \cdot 2$ & 72 & 1.96 & 213.9 & 43.9 & 64.9 \\
\hline
\end{tabular}

$\mathrm{AZ}=$ azimuth angle $\left({ }^{\circ}\right) ; \mathrm{EL}=$ elevation angle $\left({ }^{\circ}\right) ; \mathrm{RM}=$ relative magnitude $(\%) ; \mathrm{RA}=$ relative area $(\%) ; \mathrm{AD}=\mathbf{a b s o l u t e}$ duration $(\mathrm{ms}) ; \mathrm{RD}=$ relative duration $(\%) ; T=$ time of occurrence of this vector from onset of $Q R S(m s) ; M=$ magnitude of the maximal vector (mV); $1 / 2$ Time vector =location of the half time $Q R S$ vector; $R P I=$ right posteroinferior; $L P I=$ left posteroinferior; $R A I=$ right anteroinferior; $R P S=$ right posterosuperior; $R A S=$ right anterosuperior; $\mathrm{FP}=$ frontal plane; $\mathrm{HP}=$ horizontal plane; $\mathrm{CW}=$ clockwise ; $\mathrm{CCW}=$ counterclockwise.

feriorly oriented $\left(30 \cdot 2^{\circ}\right.$ in group $\mathrm{B}, 18 \cdot 2^{\circ}$ in group A). The mean azimuth angle showed that in group $\mathrm{B}$, the initial vectors were less anterior and more leftwards $\left(38.9^{\circ}\right.$ in group $B, 57.1^{\circ}$ in group $\left.A\right)$ and the maximal vector was more anterior and rightwards $\left(197.6^{\circ}\right.$ in group $B, 243.7^{\circ}$ in group A).

In 3 cases, the initial segment was transversely rather than superiorly oriented (null value of the elevation angle). At the same time, the value of the elevation angle of the maximal vector was very low $\left(4^{\circ}, 0^{\circ}\right.$, and $-4^{\circ}$, respectively). Therefore, in these 3 cases, the opposite direction of the initial and maximal vectors remained as apparent. Thus a null value for the elevation angle of the early QRS forces is compatible with criterion A.

The importance of the initial forces developing in the left anterosuperior octant, as determined by the magnitude of the maximal octantal vector, as well as by the area and duration of these forces, was found to be variable. There are some external factors which can interfere with the magnitude of these initial vectors in left posterior fascicular block. First, possible interaction from an inferior wall myocardial infarction has rarely been discussed (Castellanos et al., 1972). Isolated inferior wall myocardial infarction generally increases the initial QRS forces located in the left anterosuperior octant.
Medrano et al. (1971) showed in dogs that the production of left posterior fascicular block could decrease or even mask the electrocardiographicvectorcardiographic signs of a coexisting inferior wall myocardial infarction; Bobba et al. (1972) reported 2 cases where left posterior fascicular block during an exercise test occurred concomitantly with decrease of the pathological q waves in leads II, III, and aVF.

In our series, there were 3 cases of inferior wall myocardial infarction. The tracing of case 10 is difficult to analyse in this respect. In 2 cases (5 and 17), the usual vectorcardiographic criteria of inferior wall myocardial infarction were not fulfilled; moreover, the duration of the initial forces was shorter (12 and $13 \mathrm{~ms}$ ), the area developed by these forces was smaller $(<1 \%)$ and their magnitude was lower ( 8 and $9 \%$ ) than the average for the total group.

This 'masquerading effect' of a left posterior fascicular block on concomitant inferior wall myocardial infarction can be explained by the pathophysiology of this type of intraventricular conduction defect: when the left posterior fascicular block develops, the initial left activation relies solely on the anterosuperior fascicle, therefore ignoring the posteroinferior wall. If the latter is 


\begin{tabular}{lllll}
\hline $\begin{array}{l}\text { Left/total } 1 / 2 \text { time } \\
\text { area (\%) vector }\end{array}$ & $\begin{array}{l}\text { Rotation } \\
\text { duration FP } \\
\text { (ms) }\end{array}$ & $\begin{array}{l}\text { QRS } \\
\text { axis } \\
\left(0^{\circ}\right)\end{array}$ & $\begin{array}{l}\text { Qorq in SIQIII } \\
\text { all II,II, pattern } \\
\text { aVF }\end{array}$ \\
\hline
\end{tabular}

\begin{tabular}{rrrlllll}
52 & RPI & 98 & CW & CCW & 90 & + & + \\
53 & RPI & 90 & CW & CCW & 90 & + & + \\
43 & RPI & 95 & CW & CCW & 110 & + & + \\
36 & LPI & 95 & $\mathbf{8}$ & CCW & 60 & - & + \\
44 & RPI & 100 & CW & CCW & 80 & + & + \\
39 & RPI & 108 & CW & CCW & 100 & - & + \\
17 & RPI & 90 & CW & CCW & 110 & + & + \\
4 & RPI & 95 & CW & 8 & 170 & + & + \\
44 & RPI & 90 & CW & 8 & 130 & - & + \\
26 & RPS & 110 & CCW & 8 & 180 & + & + \\
\hline 35.8 & & $97 \cdot 1$ & & & 112 & & + \\
\hline
\end{tabular}

\begin{tabular}{rrrlllll}
52 & RPI & 170 & CW & CCW & 100 & + & + \\
41 & RPI & 94 & CW & 8 & 90 & - & + \\
14 & RPI & 125 & CW & 8 & 100 & + & + \\
12 & RPI & 148 & CW & CCW & -140 & + & + \\
40 & RPI & 150 & CW & 8 & 100 & + & + \\
16 & RPI & 175 & CW & CCW & 110 & + & + \\
11 & RAI & 130 & CW & 8 & 120 & + & + \\
11 & RAS & 180 & 8 & CCW & 180 & - & + \\
\hline 24.6 & & 146.5 & \multicolumn{7}{c}{127.5} & + \\
\hline
\end{tabular}

injured, the electrical signs of the inferior infarction will not appear. Thus left posterior fascicular block can reduce or even suppress the signs of coexisting inferior wall myocardial infarction.

It was also found in this study that an associated right bundle-branch block would increase the importance of the initial QRS forces of left posterior fascicular block. After exclusion of the 3 cases of inferior wall myocardial infarction, the mean values for group B (with right bundle-branch block) as compared with group A (without right bundlebranch block) were, respectively, 32.5 per cent and 20.5 per cent for the magnitude of the maximal octantal vector, 4 per cent and 1.5 per cent for the relative area, and $24.9 \mathrm{~ms}$ and $17.7 \mathrm{~ms}$ for the duration of this initial segment. We, therefore, suggest that right bundle-branch block in itself can increase the initial forces developing in the left anterosuperior quadrant, and its association with a left posterior fascicular block tends to produce a cumulative effect.

As far as the electrocardiographic diagnosis of left posterior fascicular block is concerned, most authors require the presence of $q$ waves in the inferior leads (Rosenbaum et al., 1968; Cohen et al., 1968; Benchimol and Desser, 1971; Tricot et al., 1971 ; Castellanos et al., 1971; Medrano et al., 1972) or at least in lead III (Kulbertus, 1972), whereas others do not require this (Pryor and Blount, 1966; Fernandez et al., 1972). In our study, a $\mathrm{q}$ or $\mathrm{Q}$ wave was present in all 3 inferior leads in 13 out of 18 cases; it was found in leads II and III in 1 case, and in lead III only in 3 cases; no q wave was observed in 1 case: in this latter case as in 2 of the 3 cases with a q wave only in lead III, the elevation angle had a null value. As the initial segment can be transversely oriented, left posterior fascicular block could thus be diagnosed in the absence of a q wave in leads II, III, and aVF, provided that the maximal vector and the initial vectors lie in opposite directions, as discussed above.

\section{CRITERION B: MAIN PART OF QRS LOOP}

The deviation to the right of the main $Q R S$ forces is considered by most authors as the essential criterion for the diagnosis of left posterior fascicular block. This right axis shift is caused by a delay in the activation of the posterobasal region of the left ventricle. The right bundle-branch block is responsible for the delay in the inscription of the right terminal forces, but it will not significantly affect the main part of the QRS. In order to quantify this right axis deviation, we have analysed the orientation of three vectors. The maximal $Q R S$ vector was directed to the right in all cases (azimuth angle between $90^{\circ}$ and $270^{\circ}$ ). The half-time vector was also directed to the right in all but one case. The half-area vector was not oriented to the right in 3 of the 18 cases. However, in these 3 cases, the ratio of the left area of the spatial QRS loop over the total QRS area was hardly greater than 50 per cent $(52,52$, and $53 \%$, respectively), and the mean QRS axis was at $+90^{\circ}$ or $+110^{\circ}$, therefore fulfilling criterion $B$.

The individual values of the azimuth angle of both the maximal and half-area vectors showed a wide dispersion, mainly in the right posterior quadrant. These values were in general lower in group B than in group A (a difference of $46^{\circ}$ for the maximal vector and $36^{\circ}$ for the half-area vector). It can be concluded that, in the presence of left posterior fascicular block, right bundle-branch block produces an additional effect on the QRS loop, shifting the main forces slightly more anteriorly and to the right.

The values of the mean $Q R S$ axis of the electrocardiogram were also widely scattered. There was a slight difference between group A and B: in group $B$, the mean value was $15^{\circ}$ more to the right. In 3 cases, though the vectorcardiogram was characteristic for left posterior fascicular block, the mean QRS axis was not located in the right inferior quadrant of the frontal plane: it was, respectively, 
at $+60^{\circ},+80^{\circ}$, and undetermined (around $-140^{\circ}$ ). This is not surprising since there is not always a good correlation between the orientation of the maximal spatial $Q R S$ vector and the angle of the maximal vector in frontal plane (Lopes et al., 1974). Moreover, since the range of normality is different between the mean QRS axis of the electrocardiogram and the angle of the maximal $Q R S$ vector in the frontal plane, the criteria for left posterior fascicular block based on these two values should necessarily be different (Poblete et al., 1974).

Although this series is too small to permit a detailed statistical analysis, we have examined other factors that might influence the orientation of the QRS loop in left posterior fascicular block. Five parameters were studied: the azimuth and elevation angles of both the maximal and half-area vectors, and the mean $Q R S$ axis of the electrocardiogram. There was no apparent correlation with left ventricular hypertrophy, inferior wall infarction, or the position of the heart within the thorax as judged from chest $x$-ray films. Two factors seemed, however, to play a significant role: (1) the presence of complete right bundle-branch block and (2) the degree of cardiomegaly. On the basis of the cardiothoracic ratio, we have considered 4 degrees of cardiomegaly: nil, moderate, severe, and very severe. The elevation and azimuth angles represent the average values of both the maximal and half-area vectors.

Fig. 2A shows that cardiomegaly is associated with a decrease of the elevation angle and, therefore, with a more horizontal loop. The cases with right bundle-branch block have higher values of the elevation angle, corresponding to more vertical loops. But in these cases, the cardiomegaly acts in the same way: in advanced stages, it brings the elevation angle toward a null value.

In Fig. 2B, it can be seen that cardiomegaly is also associated with a decrease of the azimuth angle

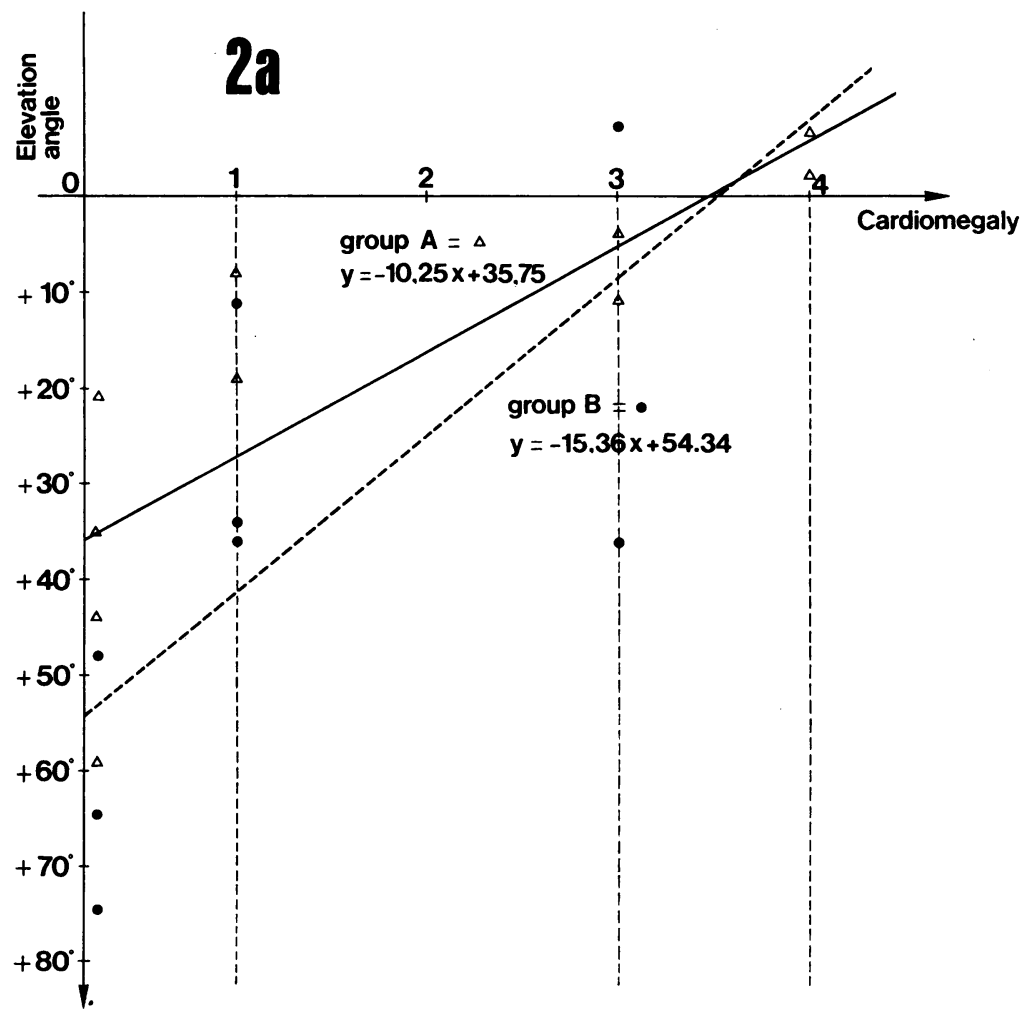

Fig. 2 Orientation of the main $Q R S$ forces as related to the degree of cardiomegaly (abscissa). Individual values of group $A$ (isolated left posterior fascicular block) $=\triangle$. Individual values of group $B$ (left posterior fascicular block + complete right bundle-branch block) $=0$. Best fitting line for group $A=-$ - and for group $B=---$ least $^{-}$ square method). (a) Ordinate: average of the individual values of the elevation angle of both the maximal and halfarea vectors. (b) Ordinate: average of the individual values of the azimuth angle of both the maximal and halfarea vectors. (c) Ordinate: individual values of mean $Q R S$ axis of the electrocardiogram. 

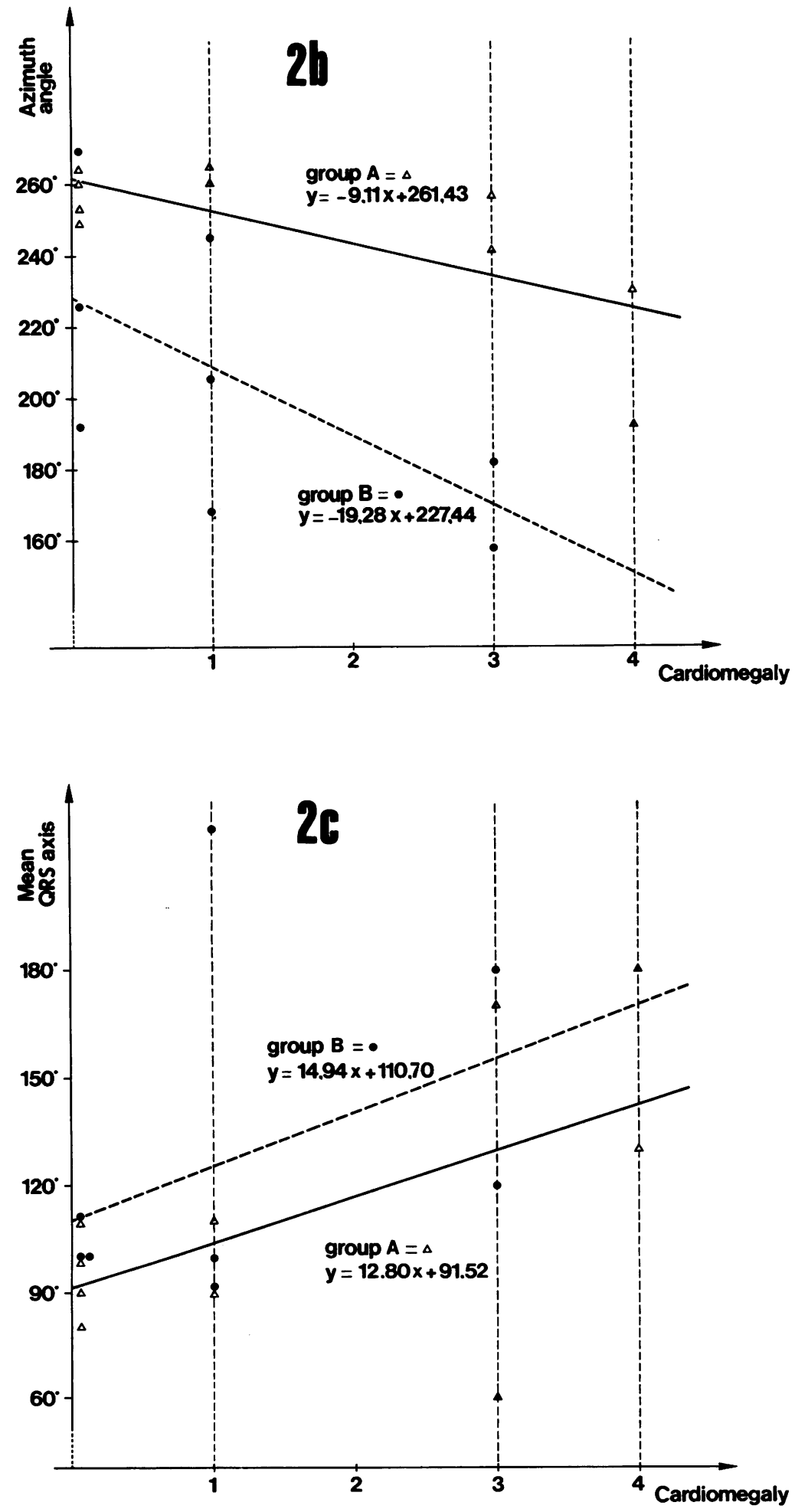
and thus with displacement of the loop to the right and anteriorly. The cases with right bundlebranch block already had lower values of the azimuth angle: in these cases, the cardiomegaly adds its own effect to the anterior shift of the QRS loop. This is shown in the figure by the divergence of the two straight lines.

Fig. 2C shows a similar effect: cardiomegaly is responsible for a rightward shift of the mean $Q R S$ axis, even more obvious in cases with right bundlebranch block.

The presence of cardiomegaly tends to decrease the values of both the azimuth and the elevation angle of the main QRS forces. In 3 cases in this series, the latter had a negative value (loop being superiorly oriented). This shows the important influence of cardiomegaly which can produce a superior displacement of the QRS loop in some cases of left posterior fascicular block. Therefore, one cannot retain the inferior orientation of the QRS as a valid criterion of left posterior fascicular block. This is why our criterion $B$ does not consider the elevation angle, but only the azimuth angle, i.e. the rightward deviation of the QRS.

Most previous publications stated that the direction of the rotation of the frontal QRS loop is usually clockwise in left posterior fascicular block. This clockwise rotation was observed in 15 cases of our series. It was counterclockwise in 1 case (case 10) and showed a figure-of- 8 in 2 cases (cases 4 and 18). But in these 3 cases there was important cardiomegaly, and the elevation angle was low or even negative (between $+4^{\circ}$ and $-15^{\circ}$ ). Therefore, just as the elevation angle could be influenced by other factors, the rotation of the frontal QRS loop should not be considered among the vectorcardiographic criteria of left posterior fascicular block.

PRESUMPTIVE CRITERIA OF LEFT POSTERIOR FASCICULAR BLOCK

In addition to the vectorcardiographic criteria $A$ and $B$, the diagnosis of left posterior fascicular block in this series was supported by several other considerations which represent useful presumptive criteria.

\section{(1) Atrioventricular block (AV block)}

Four patients had a history of Adams-Stokes syncope. The duration of the PR interval was $180 \mathrm{~ms}$ or more in 6 patients. In 3 others, there was transient complete or incomplete AV block. The mean value of the PR interval was slightly greater in group B (172 ms) as compared with group A (156 ms).

\section{(2) Progressive or variable intraventricular conduction} defects

These, which were present in 10 of our patients, appear to be of great diagnostic value. In 6 cases, there was a transient conduction defect such as right bundle-branch block, left bundle-branch block, or AV block of various degree, which disappeared during the follow-up period or was replaced by another type of conduction defect. In 4 cases, the conduction defect progressed and became permanent.

The condition known as 'hémibloc à bascule', i.e. left anterior fascicular block evolving into left posterior fascicular block (Rosenbaum et al., 1969a, b) was found in 3 patients (cases 9, 11, 17) who had in addition partial AV block.

\section{(3) Paradoxical right axis deviation}

In subjects with clinical conditions usually causing left axis deviation, such as a horizontal heart or left ventricular hypertrophy, the paradoxical finding of right axis deviation strongly suggests the existence of left posterior fascicular block. This was the case in half of our patients who had a left ventricular overload.

\section{OTHER CRITERIA OF LEFT POSTERIOR}

FASCICULAR BLOCK

According to Watt and Pruitt (1969) and Medrano et al. (1972) the QRS duration can be slightly increased by about $10 \mathrm{~ms}$, in isolated left posterior fascicular block. In group A of this series, the mean QRS duration was 97 ms. However, cases with a QRS duration less than $90 \mathrm{~ms}$ had been excluded from this study (see methods). On the other hand, the 4 patients in group $A$ who displayed a QRS duration longer than $95 \mathrm{~ms}$ had left ventricular hypertrophy or myocardial infarction: these conditions could account for a slight increase in the QRS duration. Therefore isolated left posterior fascicular block does not in itself seem significantly to increase the QRS duration. This is also supported by the fact that in group A there was apparently no significant delay of the late portion of the QRS loop in any planar projection, nor was there any delay on the curve of the linear velocity of the spatial vector.

The presence of right ventricular hypertrophy or overload makes the diagnosis of left posterior fascicular block impossible. The most usual pattern (type c) of right ventricular hypertrophy with a QRS loop orientated posteriorly and to the right is quite similar to the left posterior fascicular block pattern, and distinction is impossible on the basis of electrocardiographic or vectorcardiographic criteria alone (Strickland et al., 1972). On 
the other hand, in more severe cases of right ventricular hypertrophy, with a distinct rightward and anterior displacement of the mid and late parts of the QRS loop, the diagnosis of right ventricular hypertrophy is more obvious, though left posterior fascicular block could still be associated with the right ventricular hypertrophy.

The SIQIII pattern has been considered by some authors as characteristic of left posterior fascicular block. Rosenbaum et al. (1969b) reported several cases where the SIQIII pattern occurred concomitantly with intermittent left posterior fascicular block. In fact, our criteria A and B, as previously described, correspond respectively to the existence of a $Q$ wave in lead III and an $S$ wave in lead I. These electrocardiographic criteria were present in all but one patient. However, right ventricular overload is another possible cause 0 SIQIII pattern (Strickland et al., 1972). Later Scott (1971) suggested that acute cor pulmonale could lead to myocardial ischaemia, which, in turn, could induce transient left posterior fascicular block.

\section{References}

Arnaud, P., Martinez, Y., and Lanoue, J. C. (1968). Vectocardiographe à mémoire à tores. Symposium d'Informatique Médicale, Toulouse, France.

Benchimol, A., and Desser, K. B. (1971). The Frank vectorcardiogram in left posterior hemiblock. Fournal of Electrocardiology, 4, 129-136.

Bobba, P., Salerno, J. A., and Casari, A. (1972). Transient left posterior hemiblock. Report of four cases induced by exercise test. Circulation, 46, 931-938.

Castellanos, A., Chapunoff, E., Castillo, C. A., Arcebal, A. G., and Lemberg, L. (1972). The vectorcardiogram in left posterior hemiblock associated with inferior wall myocardial infarction. Chest, 61, 221-227.

Castellanos, A., Chapunoff, E., Lemberg, L., and Portillo, B. (1971). The vectorcardiogram in left posterior hemiblock. Vectorcardiography 2. In Proceedings of the XIth International Symposium on Vectorcardiography, New York, pp. 264-271. Ed. by Irwin Hoffman. North Holland, Amsterdam.

Castellanos, A., and Lemberg, L. (1971). Diagnosis of isolated and combined block in the bundle branches and the divisions of the left branch. Circulation, 43, 971-976.

Chou, T. C., Helm, R. A., and Kaplan, S. (1974). Clinical Vectorcardiography, p. 161. Grune and Stratton, New York.

Cohen, S. I., Lau, S. H., Stein, E., Young, M. W., and Damato, A. N. (1968). Variations of aberrant ventricular conduction in man: evidence of isolated and combined block within the specialised conduction system. An electrocardiographic and vectorcardiographic study. Circulation, 38, 899-916.

Fernandez, F., Heller, J., Trevi, G. P., Rabenou, S., Scebat, L., and Lenegre, J. (1972). The QRS loop in left anterior and posterior hemiblocks. Vectorcardiographic study during selective coronary arteriography. American fournal of Cardiology, 29, 337-343.
Kulbertus, H. (1972). Contribution à l'étude des blocs segmentaires de la branche gauche du faisceau de His et de leurs associations avec le bloc de branche droit. Thèse, Liège.

Lemberg, L., Castellanos, A., and Arcebal, A. G. (1971). Re-evaluation of septal activation in the human heart with special reference to the spatial orientations of the initial QRS vectors in intermittent left hemiblocks. Vectorcardiography 2. In Proceedings of the XIth International Vectorcardiography Symposium, New York, p. 257. Ed. by Irwin Hoffman. North Holland, Amsterdam.

Lopes, V. M., Pereira Miguel, J., Dos Reis, D. D., Da Costa, B. C. B., and De Padua, F. (1974). Left-posterior hemiblock. Clinical and vectorcardiographic study of twenty cases. Fournal of Electrocardiology, 7, 197-214.

Medrano, G. A., Brenes, C. P., De Michell, A., and SodiPallares, D. (1972). Clinical electrocardiographic and vectorcardiographic diagnosis of left posterior subdivision block, isolated or associated with right bundle branch block. American Heart fournal, 84, 727-737.

Medrano, G. A., Brenes, C. P., and Sodi-Pallares, D. (1971). Necrosis of the posterior aspect of the free left ventricular wall associated with block of the posterior subdivision of the left bundle branch of His. fournal of Electrocardiology, 4, 44-49.

Nicolai, P., Delaage, M., Medvedowsky, J. L., and Barnay, C. (1974). Les hémiblocs gauches postérieurs. Données actuelles. Annales de Cardiologie et d'Angeiologie, 23, 307316.

Poblete, P. F., Kini, P. M., Batchlor, C. D., and Pipberger, H. V. (1974). Evaluation of frontal plane QRS loop rotation in vectorcardiographic diagnosis. fournal of Electrocardiology, 7, 287-294.

Polu, J. M., Gilgenkrantz, J. M., and Faivre, G. (1972). Le diagnostic vectocardiographique des hémiblocs de branche gauche isolés et associés à un bloc de branche droit ou à un infarctus du myocarde. Archives des Maladies du Coeur et des Vaisseaux, 65, 1041-1068.

Pryor, R. (1972). Fascicular blocks and the bilateral bundle branch block syndrome. Editorial. American Heart fournal, 83, 441-446.

Pryor, R., and Blount, S. G. (1966). The clinical significance of true left axis deviation. Left intraventricular blocks. American Heart fournal, 72, 391-413.

Rizzon, P., Rossi, L., Baissus, C., Demoulin, J. C., and Di Biase, M. (1975). Left posterior hemiblock in acute myocardial infarction. British Heart fournal, 37, 711-720.

Rosenbaum, M. B. (1970). The hemiblocks: diagnostic criteria and clinical significance. Modern Concepts of Cardiovascular Disease, 39, 141-146.

Rosenbaum, M. B., Elizari, M. V., and Lazzari, J. O. (1968). Los Hemibloqueos. Editorial Paidos, Buenos Aires.

Rosenbaum, M. B., Elizari, M. V., Lazzari, J. O., Nau, G. J., Levi, R. J., and Halpern, M. S. (1969a). Intraventricular trifascicular blocks. The syndrome of right bundle branch block with intermittent left anterior and posterior hemiblock. American Heart fournal, 78, 306-317.

Rosenbaum, M. B., Elizari, M. V., Lazzari, J. O., Nau, G. J., Levi, R. J., and Halpern, M. S. (1969b). Intraventricular trifascicular blocks. Review of the literature and classification. American Heart fournal, 78, 450-459.

Rubel, P., Arnaud, P., and Prevôt, D. (1975). Système d'aide à la décision. Application à l'interprétation automatique des vectocardiogrammes. International fournal of Bio-Medical Computing, 6, 193-211.

Scher, A. M. (1960). Electrical correlates of the cardiac cycle. In Medical Physiology and Biophysics, pp. 600-607. Ed. by T. C. Ruch and J. F. Fulton. Saunders, Philadelphia. 
Scott, R. C. (1971). The S1Q3 (McGinn-White) pattern in acute cor pulmonale: a form of transient left posterior hemiblock? American Heart fournal, 82, 135-137.

Strickland, A. W., Horan, L. G., and Flowers, N. C. (1972). Gross anatomy associated with patterns called left posterior hemiblock. Circulation, 46, 276-282.

Tricot, R., Valere, P. E., and Guerot, Cl. (1971). Association bloc de branche droit et hémibloc intraventriculaire postérieur gauche. Archives des Maladies du Coeur et des Vaisseaux, 64, 169-189.

Varriale, P., and Kennedy, R. J. (1972). Right bundle branch block and left posterior fascicular block. Vectorcardiogra- phic and clinical features. American fournal of Cardiology, 29, 459-465.

Watt, T. B., and Pruitt, R. D. (1969). Left posterior fascicular block in canine and primate hearts. An electrocardiographic study. Circulation, 40, 677-685.

Requests for reprints to Dr. P. Arnaud, Hôpital Cardio-Vasculaire, BP Lyon Montchat, 69394 Lyon Cedex 3, France. 